\title{
398 The Journal of Laryngology and Rhinology.
}

cystic sarcoma. This is the eleventh case in which Mr. Browne has more or less entirely removed the thyroid gland, and all have recovered with only one recurrence. In the latter case the operation was confined to removing the isthmus.

R. Norris Wolfenden.

Horsley, Victor (London). - Note on a Possible Means of Arresting the Progress of My.ricd ma, Cachexia Strumifriva and Allied Discases. "Brit. Med. Journ.," February 8, isgo.

THE author deals with the transplantation of the gland into the peritoneal cavity, after thyroidectomy, as originally designed and carried out by Professor Schiff. The author has found that the thyroid gland of the sheep very closely resembles that of man, and he accordingly suggests transplantation of the thyroid of this animal in those diseases in man which are associated with wasting of the gland, or with its removal.

Hunter Mackensie.

Holmsen, Cato (Norway). $-A$ Case of Myxactema. "Norsk Mag. fer Laegeridenskaben," March, 1890.

DESCRIPTION of a case of myxœdema in a lady, aged thirty-four when the disease began. Treatment with galvanic electricity of the head, the neck, and the sympathic nerves improved for some time the subjective symptoms. Whether there was atrophy of the thyroid gland could not be stated owing to the thickness and stiffness of the skin. This is only the third case on record in Norwegian literature.

Holyer Mvgind.

Birch._My'xidema and Cretinoid Degeneration. "Volkmann's Vorträge," No. 357 .

REVIEW of the literature of this disease

Michael.

Waldo (Bristol). - Case of Acromegaly. "Brit. Med. Jour.," Feb. 8, I8go. Bristol Medico-Chirurgical Soc., 8 Jan., 1889.

NoTEs of the case of a man, aged fifty-four, the subject of this disease. Bulbar paralysis and convulsions were latterly present. At the postmortem examination "the brain was found to contain cavities in cerebrum and cerebellum."

Hunter Mackenie.

Silcock (London).-Acromeraly. "Brit. Med. Jour.," Jan. 4, 18go. Western District of the Metrop. Count. Branch, B.M.A., 2I Dec., 1889 .

Exhibition of three cases, two women and one man. The exhibitor believed that these cases were more common than was commonly supposed, simply because they had not been looked for.

Hunter Mackeniie.

\section{N O T ES.}

Dr. E. A. SpILsBury has been appointed Lecturer on Laryngology and Rhinology in the Trinity Medical College of Toronto, and Clinical Instructor in these subjects at the General Hospital.

Dr. C. TRow has been appointed Clinical Lecturer on Diseases of the Eye and Ear in the Trinity Medical College of Toronto.

A department for Throat and Nose Diseases has recently been created at the Cincinnati City Hospital, Drs. SATTLER and PIVERE having been elected Laryngologists and Rhinologists.

Witherbv \& Co., Printers, 326, High Holbo, n, W.C. 


\section{INDEX TO VOL. IV., 1890.}

A.

AnDUCTOR paralysis of the larynx of uncertain origin, two cases of, 436

Alductors of the vocal cords, bilateral paralysis of the, 34, 224, 523

Abortive treatment of acute catarrh of the nose and throat, I6o

Abscess of the frontal sinus, simulating lesions of the orbital cavity, 337

Accessory cavities of the nose, the diagnosis and treatment of the cliseases of the, 480 Acromegaly, case of, 398

Adenoid growths, a cause of deaf mutism, 28 ; in the adult, 292; complications consecutive to ablation of, 293 ; adenoid tissue at the vault of the pharynx, acute and chronic enlargements of, 77 ; the naso-pharynx and pharynx, 536 ; tumours, co-existence of cleft palate with, 293 ; vegetations at different ages of life, 523

Adhesions between the soft palate and pharyngeal walls, and method of correcting, 117 .

Administration of certain drugs by electricity, 20I

Air passages, case of forcign body in the, 477 ; foreign bodies in the, 40,41, 86, I30, 226, 35I ; hernia, and diseases of the upper, 218 ; in West Indian leprosy, 6 ; intubation in cases of foreign bodies in the, 174; menthol, in diseases of the upper, 245; papillomata of the upper, 349; Physiological and therapeutic action of certain drugs in affections of the, 99 ; relation between bulbo-nuclear diseases and obscure necrotic conditions of the upper, 486 ; relation of diseased conditions of the upper, to nasal reflexes, 469 ; syphilis of the, $348,53 \mathrm{I}$

Air tract, study of malignant disease of the upper, 483

Alveolar process, cases of necrosis of the, 14

American Laryngological Association, 27o, 295, 486, 535; Medical Association, section in laryngology, 307 ; Rhinclogical Association, 93

Amyglalitis, infectious and contagious, 158

Anasthetic apncea and its connection, 151
Aneurism, diagnosis and treatment of aortic, 262 ; thoracic, 225

Angina herpetica, case of, 467 ; localization of phlegmonous, 18 ; treatment of granular, 18

Aniline in pulmonary phthisis, 245, 375

Annual aldress of Dr. Roe, 307

Anosmia, a case which recovered after forty years, 516 ; from tobacco smoking, 468

Answer to Lacoarret, 468

Antrum disease, practical suggestions in regard to, $47 \mathrm{I}$; of Highmore, angioma ossificans in the, 74; diagnosis of empyema of the, 28; electrical illumination of the, in empyema, 164 ; empyema of the, $27,74,254,337,472$; illumination of the, $47 \mathrm{I}, 48 \mathrm{I}$; suppuration of the, 520 ; suppuration of the, secondary to caries of a canine tooth, 164

Aortic aneurism with urgent dyspnnea, 394

Aphonia, a case of hysterical, in a boy, 225 ; hysterical, 223, 224, 312 ; the treatment of hysterical, associated with hypertrophic rhinitis, 469 ; spastica, 388 Apparatus for inhalation, 375

Aprosexia, I 59 ; in what manner can it be prevented? 5 I 7

Aural complications from chronic catarrhal inflammation of the nose and throat, 324

B.

Basedow's disease ( $S_{c e}$ Exophthalmic Goitre, Graves' Disease) psychical troubles and hallucinations in, 395

Berlin Laryngological Society, 35 I

Branchial fistula, 44

British Laryngological and Rhinological Association, 284,545

British Medical Association. Annual Meet. ing. Section in Larynology, 4I8

Bronchi and lungs, cancer of the, 525

Bronchial medication by spray and tube during inspiration, a new method of, 324

Broncnial stenoses following syphilis, 533 ; patholugy of tracheal and, I33

Bronchocele, pulsating, 9I ; three cases of, 265: treated by electrolysis, 176 
Bronchus, foreign bodies in the, 40,87 , I 53, I 74, I75, 227, 269; rupture of a tubercular gland into the, 133

Buccal mucnus membrane, tumours of the glands of the, 155 ; tuberculosis, 69

Bursa of Luschka, the, 166; pharyngea, catarrh of the, 217

Bursitis pharyngea, acute, 339

\section{C.}

CAFFYN's liquor carnis, 299

Calcareous concretions in fits of coughing, 353

Calculus, nasal, from a girl of ten, 257 ; salivary, 68, I54; removed from Wharton's duct, $25 \mathrm{I}$

Cancer, concerning the laryngoscopical diagnosis of, 482

Cancrum oris, case of, II 4

Catarrh, chronic nasal, 97, 123; in Vermont, 468 ; ordinary case of nasal, 21 ; retro-nasal, and its relation to Torn waldt's disease, 224 ; treatment of nasal, 21. (See also Nasal Rhinitis.)

Cautery loop for lateral pharyngitis, 15

Certain phenomena of the menopause of genito-nasal origin, 124

Cheek, rodent ulcer of the, 153

Choanæe, curious case of occlusion of the, 337

Chromic acid, poisoning by, 108

Cleft palate, affections of speech in, 15 ; in hare-lip, \&c., 207

Cocaine, action of, 150 ; habit in diseases of the throat and nose, 69,107 ; in eye, ear and throat practice, I50; on the indiscriminate use of, 269 ; poisoning, 376 ; toxic action of, 63

Cold snare and écraseur combined, I49

Common cold, treatment of a, 17, 203, 245

Communication from the ambulatorium of

Dr. Michelson, 244

Congenital syphilis, 25 I

Congress, tenth international, 178, 413, 478, 528; French Laryngological, 291

Contra-laryngoscope, 201

Coryza, pseudo-membranous, 515

Cough and tracheotomy, 517

Croup and diphtheria, discussion on, 324 , 334 ; intubation of the larynx in, 462 , 463; membranes in a girl of twelve, 153; my first intubation in, 174; or diphtheria ? I6I ; treatment of, 248, 330. (See also Diphtheria.)

Cyst, sublingual sebaceous, 14

Cysts, laryngeal, 534

\section{D.}

Diphtheria and Croup 377 ; and croup in Prussia, 334, 506; and facial erysipelas, 46I ; and measles, 334 ; avian, origin of, 460 ; bacillus, researches on, I09; communicaterl through milk, I12, 376 ; contagiousness of, 248 ; degeneration of the muscles of the pharynx in,
506 ; erysipelas following pharyngeal, 249 ; etiology of, 203, 247 ; eucalyptus inhalations in, 377 ; faucial, 334 ; general remarks on, 377; in Berlin, 204; in Nuremberg, 152 ; intubation in laryngeal, 378 ; nature and caure of, 249 ; nonidentity of with that of birds, 460 ; nourishment in, 248; on, I 1 2, 249, 333, 507 ; of the pigeon communicated to man and child, 506; personal prophylaxis in, 151 ; preventive measures for, 505 ; prolonged rest after, $15 \mathbf{I}$; relation of to the soil, I I 2 ; some questions concerning, 378 ; subcutaneous emphysema of the neck in, 152; the pneumonia of, in children, 248; tracheotomy in croup and, 204; two cases of, involving a wound, 66 ; treatment of, $66,113, I_{5}$, $152,204,248,334,377,381,461$; very slight, followed by severe paralysis, 506 . (Sie also Croup.)

Diphtheritic micro-organisms, 460 ; paraly. sis, 67,204 ; paralysis, rapidly fatal cases of, 67 ; poison and its effects, 505 ; sore throat and bichloride of mercury, 506

Diseased conditions of the larger respiratory passages, 218

Dysphonia, a case of, 389 ; spastica, 78

\section{E.}

EAR, cholesteatoma of the, 316 ; the use of electricity in diseases of the, 309

Ecraseur, new wire, 484

Electric illuminating apparatus, 243, 244

Electrolysis, effects and application to solid tumours, 65 ; endo-laryngeal, 130 ; treatment of chronic tubercular infiltration by, 65

Epiglottis, case of myxoma of the, 488

Epilepsy of reflex nasal origin, 23

Epistaxis, 216; chromic acid in habitual, 519 ; counter-irritation over the liver in, 519; simple method of obtaining complete disappearance of, 163 ; therapeutic indications of, 163

Exophthalmic goitre (Se.' Graves' Disease, Basedow's Disease, Thyroid Gland); consecutive to ablation of the ovaries, 527 ; ideas of persecution in, 176 ; nature and treatment of, 477 ; treatment of, by faradization, 527

\section{F.}

FACE, total re-section of the bones of the, I64

Falsetto voice, case of, 168

Fatal poisoning from chlorate of potash, IO7

Fauces, a hiatus in the anterior pillar of the, etc., 467 ; significance of perforations through the anterior pillars of the, 16

Faucial anil pharyngeal tenesmus, on, 447 
Forceps for pharyngeal tonsil, a new and modified, 201

Fraenkel's address, 4 I 8

Frontal bone, cholesteatoma of the, $7 \mathbf{I}$

Functional aphemia, remarks on, 452

\section{G.}

Gaudeamus igitur, 416

Glossitis, and case of hemorrhagic, 1 ; and ulcer of the tongue in a cliabetic, 157

Glotlic spasm, treatment of, 167

Glottis, action of the muscles of the, 346 ; acute colema of, following the use of iodide of potash, 260 ; co-ordinate spasm of the, 223; in singing, the action of the, 485 ; physiology of the, 346 ; the physiology of the muscles of the, 166

Giycosuria, some obscure points in con. nection with, 230

Goitre, a case of, 396 ; division of the isthmus in, 177 ; enucleation of, by Socin's method, 137 ; exophthalmic, 138 , I 39, 477, 527 (Sie also (iraves' I)isease, Basedow s Isease, and Thyroid Gland); exophthalmic and allied neuroses, 139; exophthalmic, and celema of the glottis, 230 ; fibru-cystic, 284

Goitre, preliminary note on the study of, 265 ; retro-stemal asphyxiative cystic, 43 ; treatment of, by injection of tincture of ioline, 137

(ivitres, sporadic infectious, 526 ; surcsical andtomy of goitres and pathology of accessory, 265, 396; two extirpations for asphyxiative, 229

Granular angina, the treament of, 158

Graves' disease (See Exophthalmic Goitre), I 39

Gullet, case of spasmodic stenosis of the, $3^{82}$

Gum, polypus of the, I I4

\section{H.}

HARE-LIP, 68 , and cleft palate, cases of, 207

Hay fever and hay asthma, 257

Herpetiform syphilitic chancre of the lower lip--error of diagnosis, 508

Hoarseness and loss of voice, caused by a wrong rocal method, 539

Hot-air inhalations in pulmonary tuberculosis, I 30, I 50

Hypertrophy of the bones of the face, and of the hyoid bone, 254

Hypnotic mutism, a case of, 293

Ilysteria, 79, and nasal disease, 533

Ilysterical aphonia, 3 I 2 ; laryngismus, 223; mutism, 348 ; tremor, aphonia, and stuttering, 522

\section{I.}

Ictroryot, lanoline soap, I4t Ictus, laryngeal, $3+7$
Illuminator, 244

Imaginary bodies in the throat, $5 \mathrm{I}$ I

Imperforate auditory canals, 32 I

Importance of preliminary treatinent of the nasal micous membrane before operation, 317 ; of surgical means applied to the naso-pharynx in the case of nasopharyngeal and middle ear catarrh, 319

Improved spray producer, 504

Influenza, diseases of the upper air tract following, 387 ; laryngeal and pharyngeal manifestations of, 387 ; laryngitis after, 221,346 ; ulceration of the vocal cords in, 387

fnhaler, new, 269

Instrument for operation upon sub-glottic tumours, 149

Instruments, 63

Intra-laryngeal injections in pulmonary affections, 39

Intra-nasal disease and asthma, 257 ; growth, 2I2; sclerosis, the pathology and treatment of, 258 ; surgery of the present day, the legitimacy of the, 255

Intubation, case of difficulty in removal of the canula overcome by, 222; an unusual case of laryngeal, 174, and tracheotomy, 66 ; eleven cases of, ros; for croup, the first, in Italy, 65; my fifth, in laryngeal croup, 335 ; of the larynx in croup, 315 ; on, 66, 131, 262, 394, 485 ; aersus tracheoumy, 60

Iodol in tubercular laryngitis and pharyn gitis, 31

\section{J.}

Jacobsox's "Algosis Faucium Miphtheritica," I 57

\section{K,}

KocH's bacillus in the cliagnosis of tuber. cular laryngitis, 3 I

\section{L.}

\section{LANOLINE toilet soap, $\mathbf{1 4 4}$}

Laryngeal affections, cases of unexpected sudden death in, 39 ; affections in phthisical persons, 260; and other crises in tabes, 262 ; cancer, origin of, $4 \mathrm{~S}_{3}$, car: cin $m a$ 220, 393 (See Larynx); cysts, 534 ; distase in tuberculosis, the treatment of, 420,431 ; epitheliuma, extir. pation of, 393 ; fracture, cured ca-e of, 524; growth, removed by endo-Iaryngeal method, 389 ; growths, $28_{5}$; growths, case of thyrotomy and removal, I68; growths, spontaneous disappearance of, after tracheotomy, I6S, 259 : growths, the question of benign into malignant, 169 ; ictus, 33 ; motor centre, and the intra-cranial filmen procecting: 
from it, I79; movements, meth ds of demonstrating, 529; obstruction in the adult-treatment by intubation, 13I ; cedema following iodide of potash, 474 ; operations, casuistics of, 37 ; papillary polypus, 35 ; paralysis, cases of, 78 , 523 ; phthisis caused by cohabitation, 3I ; phthisis, treatment of, 388, 529, 530 ; polypus, 35 ; spasm, 522 ; stenosis of syphilitic origin, 80 ; stenosis from cancer of the œesophagus, 225 ; stridor, congenital infantile, I3I; syphilis, 3I, I 71

Laryngeal tuberculosis, 222, 387 ; diagnosis and tre,tment of, 31 ; etiology of, 524 ; of silerous form, 32 ; treatment of, by creolin and naphthol, 26I ; treatment of by menthol, 202 ; styron and Peruvian bals am in, 476 ; two cases of cured, 260 ; Wiegert's method in, 260, 375 ; tumour cured apparently by internal medication, 82 ; tumour, evulsion of a, 475 ; tumour, rare case of, 535 ; ulcers, etiology of tubercular, 79 ; vertigo, 33

Laryngectomy, 259

Laryngismus, elongation of uvula as a cause of, 341 ; hysterical, 223 ; in young children, 346 ; stridulus and eclampsia, \&c., 33 ; with tetany, 223

Laryngitis abscedens following influenza, 221 ; acute catarrhal, 30 ; hæmorrhagic and influenza, 346 ; inter-arytenoidean, 79 ; obstructive, \&c., 474 ; pregnancy in dry, 387 ; subglottica hypertrophica, 348

Laryngo-fissure, 483 ; for laryngeal growths, 36,83 ; papilloma of left vocal cord, $35^{\circ}$

Laryngo-pharynx, tooth plate in the, 269

Laryngology, on the teaching of, 4 is

Laryngoplegias, unilateral, and their diagnostic value, 523

Laryngoscopical examinations in tabes dorsalis, 224

Laryngo-stenosis from a foreign body, 524

Laryngotomy and dilatation of laryngeal strictures, 524 ; inter-crico-thyroidean, 173

Laryngo-tracheal fracture, etc., 392

Larynx, a case of lupus of the, I70; abscess of the, 474 ; acute celema of, in mumps, 347 ; and pharynx, lupus of the, 84 ; and pharynx, acute infectious phlegmon of the, 532 ; angrioma of the, 220 ; cancer of the, 168, 482; cartilaginous tumours of the, 557 ;

case of leprosy of the, 5IO; case of papilloma cured by intubation, 475 ; case of thyrotomy for foreign body in the, 172 ; catheterism of the, 262 ; cavernous angioma of the, 259 ; central motor innervation of the, $127,167,225,528$; cicatricial closure of the, 39 ; combination of syphilis and tulerculosis of the, $53 \mathrm{I}$; congenital polyputs of the, 389 ; cured case of fracture of the, 222 ; diagnosis and treatment of cancer of the, 482 ; extirpation of hygroma of the, $221 ; \mathrm{ex}$ tirpation of the, $350,390,393$; forcign body in the, 392 ; growth of the, 268 , 285 ; hiemorrhage from the, 170 ; innervation of the, 534 ; intubation of the, 222 ; lupus of the, 347,476 ; malignant disease of the, 259 ; membranes and adhesions in the, $35^{\circ}$; modified laryngectomy for epithelioma of the, 84 ; cedema of the, 30; papilloma and tuberculosis of the, 32 ; partial laryngectomy for carcinoma of the, 308 ; perichondritis of the, 87,221 ; prolapse of ventricle and tuberculosis, 32 ; removal of tubercular tumour by laryngo-pharyngotomy, 33; respiratory centre and its relation to the, 78 ; relations of the vagus and sympathetic in the region of the, 473 ; syphilis of the, 270 ; thyrotomy for foreign body in the, 85 ; total extirpation of the, for epithelioma, 35,83 ; trea ment of cancer of the, 36 ; treatment and diagnosis of tuberculosis of the, 388 ; trichinie of the muscles of the tongue and, 35 ; tubercular and syphilitic lesions of the, 79 , 387 ; two cases of stenosis of the, etc., 475 ; typical pachyderma of the, 349 ; Weigert's hot-air apparatus in tuberculosis of the lungs and, 130,260 ; unusual manifestations of tuberculosis of the, 80,171

Latest results of laryngeal and tracheal applications to the treatment of animals, etc., 130

Leech in the sub-glottic region, 174

Leprosy, case of, 8I

Leukoplakia, 340

Lingual tonsil, hypertrophy of the, $5 \mathrm{II}$; pathology of the, 34 I

Lip, syphilitic chancre of the, I 5 ; ulcer of the, 153

Listerine, $27 \mathrm{I}$

Look beyond the nose, 488

Lupus, 153 ; of the eye and throat, 158 ; of the face and oral cavity, 270 ; of the introitus laryngis, $8 \mathrm{I}$; laryngis, $8 \mathrm{I}$; of the mouth, II 5 ; of the nose, I25

Lymphadenoma, 177

\section{M.}

\section{MACROGLOSSIA, 205}

Massage in treatment of acute catarrh of the organs of the neck, 395

Maxilla, diffuse hyperostoses of the inferior, 165 ; leontiasis of the, $21 \mathrm{I}$

Maxillary sinus, dentary cyst of the, 164

Mandarins for introduction of soft rubber tubes, 467

Mediastinal lymphatic glands, primary sarcoma of the, 220

Membranous stenosis in the sub-glottic region, treatment of, $35^{\circ}$

Menthol and oils of eucalyptus and peppermint in pulmonary phthisis, 375

Method of generating neutral fumes of ammonium chloride, 244; of trating some nasal aiterations, $3 \ 4$ 
Middle turbinated bone, cysto-pneumatic expansion of the, 213

Monochloracetic acid, 15

Mouth, d seases of the mucous membrane of the, 508 ; foreign body in the, causing ear trouble, 29I; lupus of the, II5; soor of the, 154

Mucous membranes, epidemic ulcerative inflammation of the oral and pharyngeal, 340 ; pemphigus of, 509

Mutism, a case of simulated, 167 ; hysterical, 224

Myxodema, 140, 177, 398; and cretinoid degeneration, 398 ; and sporallic cretinism, I 39 ; in a young subject, 92 ; in a man, 42 ; on a possible means of ar. resting, 398

\section{N.}

Nares, symmetrical webs in the, with post-nasal occlusion, $47 \mathrm{I}$

Naris, warty growth in the, 160

Nasalaffections, the relation between nervous diseases and, 517 ; and dental diseases, deafness as a result of, 26 ; and ear diseases, the relation between, 533 ; and retro-nasal affections, treatment of 27 ; bacteria in health, I6o ; catarrh, chronic, 468 ; catarrh, hypertrophic rhinitis or hypertrophic, 515 ; catarrh, in Vermont, 468 ; catarrh, is cure as difficult as supposed ? 514 ; catarrh, streptococcus of the mucous membranes in, 514 ; catarrh, treatment of chronic, 21, 97 ; cavities, ocular symptoms due to diseases of the, 255 ; carities, speculum for applying caustics to the, 149; cavity, diagnosis and treatment of malignant tumours of the, 518 ; cavity, osscous cyst of the, $38_{5}$; cavity, the formation of the 160 ; cylinders, medicated, in hay fever, ozona, etc , 446 ; differentiation, 160 ; disease, clsstructive, and skoliosis of the vertebral column, 533 ; disease, treatment of chronic, 468; diseases, ocular reflex symptoms in, 95 ; ecchondrotome, 63 ; fossa, a case of sarcoma of the right, 490 ; fossa, diagnosis and treatment of malignant disease of the, 194, 235; fossa, foreign body for twenty-nine years in the, 516 ; mixed tumo:r of the, 5 I8 ; fosse, galvanic current in affections of the, 27 ; fossie, papilloma of the, 217 ; hamorrhage, 322; instruments, 19; mucous membrane, prima y lupus of the, 24,215 ; myxomata, transformations of, 25 ; neurosis, some cases of, 336 ; obstruction and mouth breathing in caries of the teeth, 255; electrolysis in, 24; obstruction, the relation of, to respiratory neuroses, 2I3; pharynx, points in the pathology and treatment of diseases of the, 165; polypi, 385 ; polypi, simple methorl of removing, 5I8; polypi, specimens of unusually large, 450 ; polypus, treatment of severe cases of, 25: reflexes, 24 ; septum, deviations and spurs of the, 470,479 ; septum, etiology, significance and treatment of spurs and deflections of the, 437 ; septum, electrolysis in deviations of the, 517 ; septum, hrmatoma of the, 126, 385 ; septum, new operation for deviations of the, 470 ; septum, unnamed complication of hypertrophy of the, 384 ; speculum, self-retaining, 243 ; stenosis, Hewetson's method of forcible dilatation in, 445 ; suppuration and Tornwaldt's disease, 472 ; tube and angular powder blower, 243 .

Naso-pharyngeal carcinoma, 522 ; fibromata, 217 ; growths, 28 , 166 ; polypus, 15,473 ; scarifications, 159

Naso-pharynx, adenoid vegetations of the, 166 ; anatomy of the, 165

Neck, abscess from foreign body in the œsophagus, 43 ; congenital cyst of, 396 ; lympho-sarcoma of, 478 ; sarcoma of, 140,177

Nerve, relations of fifth cranial, II4

Nervous hysterical aphonia, and galvanization of the accessory, 473

Neuralgic headaches and migraine of nasal origin, $33^{6}$

Neuritis of the trunk of the recurrent, 34

Neuroses of the heart and diseases of the nose, 23

Neurosis of the aural apparatus, 257

New York Academy of Meclicine, 268

New wire conductor for nasal polypi, 149

Nitrate of silver, the occasional topical use of solutions of, 80

Nose, acneiform syphilide of the, I62: and accessory cavities, dry treatment of the, 521 ; and asthma, the, 272 ; and mouth, tuberculosis of the, 5 I 7 ; and throat, the reflex inflammations of the, 99 ; artificial, 122 ; black tumours of the, and air-containing polypi, 484 ; bulla ossea of the, 336 ; dermoils of the, 258 ; diseases of the accessory carities of the, 385 ; foreign body retained in the, for twentyfive years, 384 ; new method of irrigation of the, 336 ; primary syphiltic sore of the, 383 ; rare case of malformation of the, 336 ; spirometric researches in affections of the, 383 ; surgical treatment of diseases of the, 98 ; the introduction of probes into the accessory cavities of the, 338 ; warty growths in the, 537

Note on the external use of sulphate of iron, 244

Notes from practice, 248

o.

Obituary, Dr. Z. Jelenffy, 493

Observations on Malta fever, IoS

Ocular neurosis, reflex, 129

(Esophageal himorrhage, severe, 344; polypus, case of, 512 ; spasm, lue to hypertrophy of the fourth tunsil, 292

(Esophajotomy, II? 
CEsophagus, cancer of the, eroding the trachea, 209; cancer of the, with dyspnœic origin, 512 ; cancerous stricture of the, treated by intubation, II 9 ; carcinoma of the, 209; carcinoma of the, involving the recurrent nerve, $7 \mathrm{I}$; case of perforation of the, by a fish bone, 344 ; case of stricture of, 19, 253; case of stricture of-gastrotomy, II8, I I9, 159 ; cicatricial and cancerous strictures of the, 158 ; epithelioma of the, 81 ; foreign body in, in the perforation of the carotid, 513; foreign body in pesophagotomy, I20; im laction of a splinter of grouse bone in, 7 1 , I 59 ; impermeable stricture of-gastrotomy, 120 ; laryngeal stenosis, following cancer of the, 225 ; rare case of cancer of the 209 ; removal of foreign body from, by soft india-rubber tube, 253; retention tules for constriction of the, II9; treatment of stricture of, by linear electrolysis and dilatation, Ir9; unusual case of malig. nant disease of the, 254

Olfactory apparatus, the central nervous, 162 ; nerve, its tests and physiological importance, $\mathbf{I} 6 \mathbf{I}$

Ozœena, 479 ; pathogeny of atrophic, I62; therapy of, 383 ; the nature of, 125 ; the shape of the nose in, 27 ; treatment and prophylaxis of, 75,76

Original and Leading Articles: A Case of Acute Hæmorrhagic Glossitis, by Dr. Holger Mygind, I ; The Condition of the Air Passages in West Indian Leprosy, by Dr. J. D. Hillis, 6 ; Breathing during singing and Speaking, by Mr. Mayo Collier, 49 ; Epithelioma of the Thyroid Gland and Trachea, by Dr. Norris Wolfenden, 50; The Chloroform Question and the Report of the Second Hyderabad Commission, 52; The Nose and Asthma, ror; The Treatment of Stricture of the Esophagus, I06; Chronic Rheumatic Sore Throat, by Dr. Fletcher Ingals, 145 ; The Cortical Motor Laryngeal Centre and the IntraCerebral Fibres which proceed from it, by Drs. Garel and Dor, I79; A Study of the Diagnosis and Treatment of Malignant Tumours of the Nasal Fossa, by Dr. A. F. Plicque, 194,235; The Nose and Neurasthenia, 234; Un a Classification of Intra-Nasal and Nin-Plarylis:(al Diseases, by Mr. Lennox Bumne; 273 ; A Case of Fibro-mucous Polypus of the Naso-Pharynx, by Dr. C. Warden, 280 ; On the use of the Dental Drill in the Treatment of Deviations of the Nasal Septum, by Dr. A. Bronner, 282; A Case of l'rimary Sarcoma of the Tonsil, Treatment by Electrolysis-Death, by Dr. Ilolger Mygind, 3OI ; Operations up n the Larynx for Malignant Disease, 361 ; On the Indurative and Proliferative Forms of Tubercular Laryngitis, by Dis. Gouguenheim and Gluver, 365,399 ; The Tonsils and the
Adenoid Tissue of the Pharynx, 455 ; On Deviations and Spurs of the Nasal Septum, by Drs. Moure and Bergonić, 495 ; On the Nature of the Tonsils and Lymphoid Tissue of the Pharynx, by Mr. Mayo Collier, $5^{\circ 2}$

\section{P.}

PACHydermia laryngis, 219, 476, 484; diffusa, 484

Palate and tonsil, syphilitic phagœedena of the, 207; epithelioma of the soft, 16 ; tuberculosis of the soft, 16

Parosmia, 162

Parotid, mixed tumours of the, 379 ; sarcoma of the, 379 ; tumour of the, II 5

Pepsalia, 299

Perichondritis laryngea, 22I

Peritonsillitic abscess, 467

Peritracheal abscess with consequent seropurulent pleurisy, 525

Pharyngeal fibroid, 29; polypus, congenital hairy, 208; sclerosis acquired by feeding syphilitic children, 344 ; tonsil, a simple and effcctive method of anxsthetizing the, 316 ; and so-called relaxed throat, $45^{\circ}$ : hypertrophy of the, 320 ; vault, lymphoid hypertrophy of the, 320 ; tumours, rare, 533 ; ulcers, benign, 484 .

Pharyngitis, chronic fibrinous, 208

Pharyngo-laryngeal neuralgia, I 8

Pharyngo-laryngitis, iodol in tubercular, 31

Pharyngo-nasal syphilis, 208, 522

Pharyngotomia subhyoidea, $38 \pi$

Pharynx, adhesion of the soft palate to the posterior wall of the, 344 ; case of foreign body in the, ending in death. 382 ; cysts of the, 116; parzesthesia of the, I8; primary cancroid of the, 208 ; pulsating arteries in the posterior wall of the, 467 ; stenosis of the, from hereditary syphilis, I 58; syphilitic stenosis of the, 343; tumours of the, 253

Phonoto-photographic studies, 345

Pneumonia from foreign body in the lung, cured by expectoration of the body, 260

Post-nasal growths, 258, 288

Posticus muscle? What is veritable paralysis of the, 78

Posterior pharynx and tonsils as places of entry of infectious disorders 158

Primary lupus of the introitus laryngis and pharyngotomy, 8I

Ptyolite in Wharton's duct, 153

Pulsation of the soft palate and urula in aortic regurgitation, $5 \mathrm{IO}$

Pumiline liniment and ointment, $27 \mathrm{I}$

Pyoktanin in the nose and throat, 376 , 476,485

\section{R.}

RANula, I54; double, 519

Rare case of idiosyncrasy towards tannic acil, $150,202:$ tumour in a child, 526 
Recurrent paralysis, 223, 534

Reflex cry, case of, 167 ; chorea, $4^{6} 9$; neuroses of nasal origin, 122,215

Relation of peripheral irritation to diseases of the throat and nose, 516

Respiration through the nose, 74

Retro-nasal affections, with typical symp. toms, 339; tumours, technique for operations on, 339 ; ca' arrh, and Tornwaldt's disease, 383

Retro-pharyngeal ab-cess, 467

Reviews : Chronic bronchitis and its treatment, Murrell, 45; Asthma consiclered specially in relation to nasal disease, Schmiegelow, 142; The transactions of the Inter-Colonial Medical Congress of Australasia, 23I; Coca and its the ra. peutic application, Mariani, 231 ; Transactions of the American Laryngological Asso iation, 270; Pathology and therapeutics of the pharynx, nasal fossex, and larynx, Massei, 296; Cyclopredia of the diseases of children, Keating 353; The examination of the posterior laryngeal wall, Killian, 358 ; The congenital occlusions of the posterior nasal cpenings. and their treatment, 359; Diseases of the nose, Ball, 49I ; Diseases of the nose, Spencer Watson, 49I

Rhinal disease, reflex symptoms of, 95

Rhinitis atrophicans, 479; caseosa; 22, 23 ; diagnosis and treatment of, 22 ; five reasons for failure in treating, 94, 256

Rhino-chirurgical communications, 126

Rhino-laryngeal observations in influenza, 337

Rhinolith, 122, I63, 29I, 294

Rhinolithiasis, 163

Rhinologie, 145

Rhinology, therapeutic measures in, 96

Rhino-pharyngeal inflammation, treatment of, 98

Rhinoplasty, 164

Rhino-scleroma, cases of, 518

Rhinoscopia posterior, new method of, 29

Rumination in human beings, cases of, 206

\section{S.}

SAgitTal fissures of the posterior ends of both turbinateds, 470

Salivary calculus, II 4,154

Salivation, profuse, I 54

Saw, nasal, 284

Scarlatinal sore throat, on the pseudodiphtheritic, 333,376

Scrofulous glands, the treatment of, 92

Septum, abscess of the, 480 ; atrophy, hypertrophy and deviations of the, 97 ; etiology of perforations of the, 480 ; exostoses of the, 480 ; operation for correcting deviations and thickening of the cartilaginous, 258 ; perforating ulcer of the, 337 ; perforation of the, 258 ; perforation of the, in cement workers, 24 simell, microscopic anatomy of the organ of, 514 ; on measurement of the sense of, 254

Soor of the mouth, 154

Sore throat, drain, 17

Speech, affections of, in cleft palate, 15 ; classification of affections of, 44 ; functional disturbances of, 129

Spheno-maxillary region, fibro-sarcoma of the, 212

Spirome:er, a new, 300

Sputa, gangrenous, 353

Stoerk's blennorrhæa, 162

Stomatitis, contagious, $\mathrm{I}_{3}$; in blennhorr. hagic individuals, ulcerative membranous, 154 ; infectious aphthous, 12 ; in uræmic, I54; ulceralive, 340

Sterno-mastoid tumour, I 40

Stridor and attacks of suffocation in a hysterical male, 332

Struma, results of ligature of arteries in, 478

Strumous glands, operative versus therapeutic treatment of, 140

Sub-clavian artery, abnormal, 43

Sub-hyoid dermoid cyst, 44

Sub-maxillary gland, melanotic sarcoma of the, $25 \mathrm{I}$

Suicide from attempt to cut the head off from behind, 92, 93

Sulphorianic acid a solvent for medicaments, 64, 150

Superior laryngeal nerve, experiments upon the, 167 ; the surgery of, in spasmodic affections of the larynx, 34

Syphilitic chancre of the lip, cheek, and fauces, 380,463 ; stenosis, 269

Syphilis following tattooing, 68

\section{T.}

Throat affections of rheumatic origin, 69 Thrush, treatment of, by brushing, 64 .

Thymus, sudden death from hyperplasia of the, 92,527

Thyroid asthma and its surgical treatment, 228 ; body, transplantation from animals io man, 176 ; cases of cysts and adenomata of the, treated by extirpation, 89 ; congenital enlargement of the, 397; cysts, 265 ; discussion on Scheinmann's paper on cancer of the, 137 ; enlargement, 137,265 ; gland, adenoma of, in a leopard, 42, 264; gland, carcinoma of the, 230 ; gland, circumthyroid inci-ions in cancer of the, 42 ; gland, enlargement of the, 42 ; gland, the functions of the, 175; gland, two cases of malignant disease of the, 176 ; gland, tumour of the, 264 ; removal of the, 91 ; specimens, illustrating disease of the, $\mathrm{I}_{34}$; tubercle of the, 177 ; tumour, 396 ; two cases of malignant disease of the, $9 \mathrm{I}$

Thyrotomy, 173

Tinnitus aurium, the pathology and treatment of, 316

Tongue, a vegetating form of syphilis of the, 465 ; arthenion of, to the 
pharynx, 15; atrophic cancer of the, 340 ; atrophy of the right side of the, 13; black, 287 ; cyst of the, I4; eczema of the, 156 ; epithelioma of the, 156, 251 ; fungous growth of the, 15 ; glandular hypertrophy at the base of the, 135, 3ro ; hemiatrophy of the, 69,509 ; hypertrophy of the adenoid tissue at the base of the, 3 IO ; instrument for removing glandular hypertrophy of the, 466; lesions of, in syphilis, 509; lymphatic næevus of the, 205 ; papilloma of, successfully removed, 380; papilloma of the epiglottis, and base of the, 82 ; pre-cancerous condition of the, $25 \mathrm{I}$; treatment of tertiary syphilis affecting the, 465 ; vaccine vesicle on the, I I 5

Tonsil, a case of pedunculated polypus of the, I 57 ; alveola sarcoma of the, I 57 , 284 ; cancer of the, 17 ; epithelioma of the, 207; lympho-sarcoma of the, 17 ; sarcoma of the, 69 , I 57

Tonsilla pendula, 5 IO

Tonsillar chancre, importance of deep adenitis in, 157

Tonsillitis, correlation of follicular in children with other zymotic diseases, 253 ; follicular, followed by infectious phlebitis, 381 ; rapid cure for, 466 ; treatment of acute, 466

Tonsillotome, a modiified luce, I49

Tonsillotomy followed by serious hæmorrhage, 34I ; hremorrhages following, their etiology, prophylaxis and treatmert, 342 ; some untoward occurrences connected with, 342

Tonsils, hæmorrhage after removal of the, 71 ; primary carcinoma of the, 342 ; the galvano-caustic treatment of hypertrophy of the, $70,116,252$; the treatment of diseased, when unattended with hypertrophy, 70

Trachea and bronchi, physiology of the, 30 ; application of drugs by the, 525 ; examination of, through the tracheal fistula, 534; foreign body in the, 4I, 351,382 ; penetrating wound of the, 395 ; plumstone in the, 227 ; removal of a needle from the, 477

Tracheal stenoses, 263 ; on the cause of, in tracheotomized chiluren, 222 ; tumours, 534

Tracheotomies, statistics of, 83

Tracheotomy, I73; and intercricoid laryngotomy compared, 36 ; complicated by calcification of the trachea, 173 ; complications of, in old people, 485 ; entrance of air into veins during the performance of, 351 ; in croup, 508 ; in phthisical patients, 133 ; in the course of smallpox, I73; modified, 35 ; on account of a wound of the larynx, 394; results secondary to, 507 ; the performance of, in the adult, 393
Treatment of empyema of cavities with hard walls, 216

Trichloracetic acid in diseases of the throat, $64,203,504$

Tuberculosis of the gums and lip, 153

Tupelo dilators for the nose, 484

Turbinated bones, hypertrophy of the, $2 \mathrm{I} 2$; growth, large, complicated with cleft palate, 212

Turbinateds, hypertrophy of the, as a cause of weeping, 24

Typical form of lateral swelling of the external nasal wall, 470

U.

ULCER beneath the left eyelid, 153

Unilateral paralysis of the lateral cricoarytenoid muscle, 542

Upper respiratory tract, strumous disease of the, I31

Uvula, anomalies of the, II6; papilloma of the, II 5

\section{V.}

VASELINE atomizer, 546

Vereker's chloride of ammonium inhaler, 546

Vertebral artery, thrombosis of the, 13

Vertigo, remarks on, 218

Verruca duris laryngi $=476$

Vin tonique Mariani, 232

Vinolia soap, 232

Vocal cords and goitre, paralysis of the, I 68 ; bilateral paralysis of the abductors of the, 224 ; histology of the, I66; hysterical motor affections of the, 167 ; papilloma of the, 269 ; what shall we call the true? 219

Voice and the registers, the, 44 ; centre in man, the localization of the cortical, 345 ; effects of castration on the, 168 ; the falsetto, 168 ; the, of children, and singing in schools, the, 522

\section{W}

WALLICH inhaler, the, 299

Wharton's duct, obstruction of, 69

Whooping cough, antipyrin in, 64,378 ; cases of infection by staphylococcus aureus in, 504; effect of bromoform in, 504 ; hydrate of terpene in, 504

Wounds of the cavum pharyngeum, 5 II

\section{$\mathrm{X}$.}

Xerostomia, 379 
